\title{
Online Language Teaching: Methods and Strategies, Possibilities and Opportunities
}

\author{
Bharathi S. Rai ${ }^{1,2}$ \& Rajeshwari M. ${ }^{3}$ \\ ${ }^{1}$ Research Scholar, College of Social Science \& Humanities, Srinivas University, Mangalore, \\ India \\ ${ }^{2}$ Assistant Professor, Dept of English, St Philomena College, Puttur, India \\ Orcid ID: 0000-0001-9613-4967; Email: raibharathi@ yahoo.com \\ ${ }^{3}$ Research Scholar, CCIS, Srinivas University, Mangalore, India \\ Orcid ID: 0000-0002-3561-5123; Email:rajimuraleedhar@gmail.com
}

Area/Section: Business Management.

Type of the Paper: Review Paper.

Type of Review: Peer Reviewed as per $|\mathrm{C}| \mathrm{O}|\mathrm{P}| \mathrm{E} \mid$ guidance.

Indexed in: OpenAIRE.

DOI: https://doi.org/10.5281/zenodo.4606936

Google Scholar Citation: IJMTS.

\section{How to Cite this Paper:}

Rai, Bharathi S., \& Rajeshwari, M., (2021). Online Language Teaching: Methods and Strategies, Possibilities and Opportunities. International Journal of Management, Technology, and Social Sciences (IJMTS), 6(1), 128-141. DOI: https://doi.org/10.5281/zenodo.4606936

International Journal of Management, Technology, and Social Sciences (IJMTS) A Refereed International Journal of Srinivas University, India.

(C) With Author.

CrossRef DOI: https://doi.org/10.47992/IJMTS.2581.6012.0134

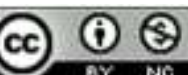

This work is licensed under a Creative Commons Attribution-Non-Commercial 4.0 International License subject to proper citation to the publication source of the work.

Disclaimer: The scholarly papers as reviewed and published by the Srinivas Publications (S.P.), India are the views and opinions of their respective authors and are not the views or opinions of the SP. The SP disclaims of any harm or loss caused due to the published content to any party. 


\title{
Online Language Teaching: Methods and Strategies, Possibilities and Opportunities
}

\author{
Bharathi S. Rai ${ }^{1,2}$ \& Rajeshwari M. ${ }^{3}$ \\ ${ }^{1}$ Research Scholar, College of Social Science \& Humanities, Srinivas University, Mangalore, \\ India \\ ${ }^{2}$ Assistant Professor, Dept of English, St Philomena College, Puttur, India \\ Orcid ID: 0000-0001-9613-4967; Email: raibharathi@yahoo.com \\ ${ }^{3}$ Research Scholar, CCIS, Srinivas University, Mangalore, India \\ Orcid ID: 0000-0002-3561-5123; Email:rajimuraleedhar@gmail.com
}

\begin{abstract}
Online Teaching has been an effective method to meet a great number of learners at the global level. Learning this way leads the eager learners to find different ways to discover new horizons of knowledge. The online content of language learning has led many information seekers to concentrate on the acquisition of exuberant language skills. This paper study various methods and techniques that could be used to connect diverse information aspirants. Challenges are also being discussed in the existing eligible system for online language teaching. The virtual classroom here is designed with cyberspace to create a language learning atmosphere. The paper outlines the reasoning, design, including the use of these lesson plans that facilitate action and reflection across the learning cycle. The techniques and approaches set out in this paper will provide insight into the outcome of the initiative. This research also provides a look at the shots of online teaching. This study examines potential approaches and techniques and explores the wider possibilities and varied prospects for achieving the objective of helping the target group of students to achieve their goals. Possibilities have brought more benefits not only to the pupils, but also to the aspirants, irrespective of their age group. It also suggests some potential online training methodologies for teachers to take classes online.
\end{abstract}

Keywords: Online Teaching, Language Teaching, Learning, Education, Virtual Classroom

\section{INTRODUCTION :}

Language plays a vital role in various facets of human life. It is not only used for communication but also as a tool for problem-solving. Language learning begins from the very cry of the infant as soon as it is born and is expanded in the association and reciprocation with the surrounding elements. People use it to acquire knowledge and share the same with the needy. Language is much essential to build a relationship with others. It helps people express their thoughts, feelings, and ideas [1]. Learning language will also open the doors of several career opportunities. It also helps in understanding the culture. Language is considered a key aspect in the future professional endeavor of pupils. Whatever be the profession say doctors to the director, teacher to technician, engineer to entrepreneur, agriculturist to astronaut language is plays a crucial role. For some people, language is a mystery for those who mastered it, it is a child's play. To learn any language a comfortable environment is the most essential. Learning language is not just learning grammar and vocabulary. It is the process of learning new things, expressions, ideas and principles. Technology is being used in every sector these days. Use of technology in the process of teaching-learning will make it more effective [2].

A course aimed at propagating or disseminating knowledge through a computer-assisted learning management system through which students are free to access the course material and progress of the academics concerned. It also offers enough opportunities for co-learners to interact online, as well as with the course preceptor. In recent settings, it is normal to see online classroom settings become an increasing amount of popular to take the intended courses to internalize. This arrangement offers the learner the flexibility of choosing to learn in real time, at any time, anytime, anywhere. This may be the need to address the question of why we study a language. Language allows us to be relaxed in any situation, as it lets us know like we are [1]. 
There is a steady upward rate of online language learning by diverse language seekers. Over the past decade, the world has seen the spread of computers and social media platforms, allowing people to stay in touch in various ways to increase their development and use internet facilities to learn and obtain knowledge in their fields of interest. Pedagogical approaches to languages may be different, because their subject matter is just communication. The skills needed for online language teaching are completely different. As a result, a joint initiative is needed to equip teachers with professional skills training to meet the needs of the coming circumstances. Despite a large number of research-based publications on computer-based learning skills, there is a lack of resources to establish online-teaching teachers and the knowledge required for the new field of online teaching [3].

Both the learners and teachers have found the benefits of recognizing how audio-visual aids help them fulfill their duties as teachers and responsibilities as learners [3]. Audio-visual courses help students learn pronunciation as they will hear native speakers of English. Audio clips help them understand the various forms of speech and the proper accent of English. It also encourages writing by offering a range of ideas after watching video clips or images. Otherwise, the mind remains like a blank sheet of paper. Audio-visual courses help students get out of the monotony of long classrooms [4]. To render the class interestingly interactive, the instructor may use images to inspire students to envision and verbalize in various angles. This class environment will instantly transform into an atmosphere of group discussion, enable them to get ideas out of their thinking that improve-spoken skill. Audio resources also help expand the learner's active listening skills [5].

\section{OBJECTIVES:}

This paper mainly highlights the use of technology in teaching languages. The objectives of this paper include

- To elucidate the methodology adopted for teaching language online

- To explore the possibilities and opportunities available for teaching language online

- To identify different tools and platforms for teaching language online

- To identify issues and challenges associated with teaching language online

\section{METHODOLOGY:}

This paper is prepared by gathering secondary data from educational websites and written articles. The assessment shall be carried out by means of research journals, papers, newspapers and websites, etc. This qualitative research is made by observing and analyzing existing knowledge on the subject using the keywords "Online Teaching," "Language Teaching," "Learning," "Education" and "Virtual Classroom," which are accessible in online articles, peer-reviewed journals, publications, and various respective portal.

\section{THE TEACHING LEARNING PROCESS:}

The teaching-learning process involves the involvement of two major entities namely learner and educator. The job of an educator is to identify the learning needs, strategies, techniques and tools that are necessary to impart knowledge. Based on the syllabus to be followed, the educator prepares a teaching plan, study material, assignments, etc., which are necessary for making the learner better understand the subject. It is the job of the educator conduct tests to assess the learners and to evaluate the outcomes [6]. The skills, techniques, tools and methods to impart knowledge play a vital role in the effectiveness of teaching. The teaching-learning process can be broadly classified as conventional faceto-face and online.

\section{(1) Face-to-face learning}

In the conventional face-to-face learning system, the students must be physically present in the classroom. It is teacher-centric one and the students listen to their teachers. In most of the situations, they will be passive listeners. The time-table for classes is fixed and the learners must attend classes regularly. Teachers guide the students and students must follow the instructions of the teacher. Since the teacher is the major source of information, there is limited scope for knowledge expansion [7]. There is a greater possibility of live interaction between the teacher and learner; also, learners have a greater level of interaction with their peers. This type of education system is considered highly effective and is being intensively practiced [8]. 


\section{(2) Online learning}

In typical cases, online classes had flexible schedules without devoting significant quality time, commuting costs and high fees. Along with various course choices, one can cope with evolving situational needs, benefit from low-investment learning and learn at one's speed, and enjoy lucrative career development [9].

In an online teaching course where a teacher encourages communication in his or her classroom, the primary responsibility is to make a good effort to develop efficient communication. His or her position during the course is to be a tutor, trustee and consultant while keeping track of the tasks assigned to him or her [6]. The instructor can provide some part of the lesson, such as when dealing with linguistic accuracy. In other situations, he is a moderator under the guise of an activity facilitator. Yet, he seldom communicates with students. Often, he is a debater, but usually he generates circumstances that direct contact with and between students. Students have a lot to do with each other. They do in many layouts and styles, such as pairs, trails, small groups, and the entire party. All of the above ought to be taken into account when a teacher dives himself in the realms of online learning as it is a grueling, arduous and challenging activity on behalf of the instructor.

Alternatively, the complexity of the social climate of the pandemic, such as COVID-19, from which the population has not recovered, has led teachers to turn to online teaching. If the pandemic persists, online language pedagogy is also intensified by the giant COVID-19 pandemic. Learners have opted to opt for common online courses such as SWAYAM, ARPIT, NPTL, MOOCS to go the extra mile in career development and faculty development programmes. Here the learners have gained a large number of benefits and that the courses have earned a high reputation. As there is a potential for individualistic learning in CALL, the extent of the growth of communicative skills is high and the individual learning style develops and improves the consistency of the learner's leadership. Confidence building thought sharing and verbal growth is a further contribution to earnings in the line of career building. Students may also use their mobile devices in online language learning wherever they are at the time of their learning activities [10].

\section{(3) Comparison between face-to face learning and online learning}

The comparison of conventional, face-to-face, classroom education with the online education approach is shown in Table 1. It indicates the merits and demerits of each other.

Table 1: Comparison between face-to face learning and online learning approach

\begin{tabular}{|c|c|}
\hline Face-to-face Learning & Online Learning \\
\hline $\begin{array}{l}\text { - The teacher delivers information to a group of } \\
\text { students who hear passively and immerse } \\
\text { themselves in whatever the teacher has gone } \\
\text { through. } \\
\text { - The tutor encourages students to learn about } \\
\text { him/her, discover new areas of expertise and } \\
\text { engage students in conversation and discussion } \\
\text { groups. } \\
\text { - The function of technology is not as high as online } \\
\text { learning. } \\
\text { - It includes more interaction. } \\
\text { - External assistance must share the learning } \\
\text { materials. } \\
\text { - A good active relationship with teacher-student } \\
\text { - Continuous student monitoring is possible. } \\
\text { - All-round development of personality with } \\
\text { opportunity to excel in extracurricular activities. }\end{array}$ & $\begin{array}{l}\text { - Teachers play the role of facilitator in the online } \\
\text { education model. } \\
\text { - The online learning approach will help promote } \\
\text { self-directed, learner autonomy with improved } \\
\text { scope for customized thought and increased } \\
\text { content interaction. } \\
\text { - The function of technology is too big to meet } \\
\text { students with subjects. } \\
\text { - Includes less interaction compared to a classroom } \\
\text { learning approach. } \\
\text { - Using the Internet for virtual classes, students can } \\
\text { easily access several resources to help the topics } \\
\text { of the course. } \\
\text { - Passive relationship with teacher-student } \\
\text { - Monitoring of students is poor. } \\
\text { - Personalized learning ensures that the student } \\
\text { stays focused on his/her unique, interested } \\
\text { learning path. }\end{array}$ \\
\hline
\end{tabular}

(4) SWOC Analysis of Online Learning

The online environment provides unparalleled opportunities for people who would otherwise have limited access to education, as well as a new model for educators in which high-quality dynamic courses 
can be created [8]. Online learning can be seen as a powerful method for inculcating information, given that the lessons are conceived and performed in an affable and thoughtful manner in compliance with the guidelines of the agencies concerned. It also helps the learner be both an online tutor and a student since both learners are part of the process. It will be obligatory on behalf of the teacher to encourage the participants to delve deeply into the material and medium, which, in turn, will promote imagination while exposing the participants to new technologies. The student should pay more attention compared to online classes and conferences, where there is a great deal of space for voice-breaking that is taken for granted in face-to-face classroom teaching. The strengths, weaknesses, opportunities, and challenges of the online education system are analyzed in Table-2.

Table 2: SWOC analysis of online education system

\begin{tabular}{|c|c|}
\hline Strength & Weaknesses \\
\hline $\begin{array}{l}\text { - It is both, self-paced and facilitator-led } \\
\text { - Development of new online resources } \\
\text { - No geographical barriers } \\
\text { - Free access to online resources } \\
\text { - Flexible schedule } \\
\text { - No interruption in course proceedings }\end{array}$ & $\begin{array}{l}\text { - Time constraints } \\
\text { - Reduced student engagement } \\
\text { - Limited scope for collaborative learning } \\
\text { - Teacher/student relationship } \\
\text { - The required additional training for both teacher and } \\
\text { students to migrate } \\
\text { - The threat of data security } \\
\text { - Requires high technical support within institution }\end{array}$ \\
\hline Opportunities & Challenges \\
\hline $\begin{array}{l}\text { - Academic collaboration } \\
\text { - Skilling in new technologies and resources } \\
\text { - Incorporation of blended learning in future } \\
\text { curriculum development } \\
\text { - To make it more convenient and accessible } \\
\text { - Development of alternative examination methods }\end{array}$ & $\begin{array}{l}\text { - Training teachers and students to get ready } \\
\text { - Coping with the attitude and behavior of online } \\
\text { learners } \\
\text { - Collaborating with diverse tools for creating a teacher- } \\
\text { - centered classroom environment of learners } \\
\text { - Lack of practical sessions and cadaveric exposure } \\
\text { - } \text { Issues with assessment } \\
\text { - Reduction in quality of resources }\end{array}$ \\
\hline
\end{tabular}

\section{TEACHING LANGUAGES ONLINE :}

The object of language teaching is seen as an instrument for transmitting meaning to someone with an intention, either through vocal expression or through writing [4]. Precision and clarity in the language have been flavoured compared to fluency, proficiency and ease in spoken English. It is commonly and deeply believed reality that those who communicate in English with clear command could be suited to any work. Indians are no exception to this fervour. Every teacher had to adopt a teaching technology that was a blackboard to help language teaching. Language teachers have practiced the grammar transformation approach, where students obey the teacher's interpretation of grammatical rules and must execute translations. The one-way transfer of information and knowledge has been introduced in this process. Teachers' blackboards were later supplemented by interactive displays as an unrivaled tool for creating a teacher-centered classroom environment.

Later in the 1970s and 1980s, the audio tape was the ideal medium for the audio-lingual process, which became popular, and the learners were made to observe audio classes where they had to experience challenging repetitive skills. In the later stages, the audio-lingual approach often fell into disrepute because of the lack of anticipated results from expensive language laboratories. This weakness can be because repeated drills focus only on language types and lack the perception of communicative context as a whole. In the late twentieth century, a trend toward communicative language teaching that demands more student participation, which saw the blossoming of two approaches as a glimpse of hope. The new learning pattern turns those who are spiritually depressed, dissatisfied, or disconnected from education into happy, curious, and speculative individuals. As a result, meaningful interactivity with the emergence of distinct approaches, namely, Cognitive approach and socio-cognitive approach was introduced. Since cognition is a psychological perception, intuition or rationalism, and comprehension through experiential learning through the senses and thought process, such an approach to communication assumes that internalizing language is an individual psycholinguistic act. With this 
understanding in their minds, the learners set a model in the minds of inhibitive cognitive awareness with perceptible and meaningful words [11].

It has been observed that there is a steady upward rate in the online learning of languages by various language seekers. Over the last decade, the world has seen the advancement of computers along with social media sites. The people can be constantly in contact with numerous ways of expanding the growth and help of internet facilities to learn and gain information in the field of once-interest. Pedagogical approaches to languages may be different, because their subject matter is just communication. The skills needed for online teaching in contrast to face-to-face language courses are uncontroversial challenging. As a result, a collaborative effort is expected to equip teachers with technical skills training to meet the needs of the coming circumstances. Despite a large number of research-based publications on computer-based learning skills, there is a lack of resources to develop online teaching teachers and the expertise needed for the new field of online teaching [12].

A course conducted to disseminate or impart knowledge through a computer-assisted learning management system in which students are free to access their course content and their progress in concerned academics. This also provides ample opportunities to communicate with the co-learners online and the course preceptor. In recent setups, it is common to witness online class settings becoming increasingly popular to take up the intended courses to internalize. This arrangement provides the learner with the comfort to choose to learn in real-time, anytime, anywhere at his or her pace. As it is a well-known fact that the expertise needed for teaching online is considerably different from that which is needed to teach language face-to-face classrooms as well as other subjects online. A teacher should know the plans and methodology to ease online learning to use the advantages of collective and individualistic learning. A teacher should have technological skills at a rudimentary stage to become an online instructor. A teacher who is teaching online should also know the limitations while adopting certain applications that curb the speed of the race. Even though there is a sufficient amount of free software at one's disposal, all those are laden with abundant drawbacks and strengths [13]. An online instructor or facilitator should be creatively proficient in his or her communicative competence.

It is observed that learning language as a subject online is harder than any other for that matter. Teaching or learning a language needs more time and patience and one rule or formula cannot be applied at every level of learning. The comprehension level of learners may vary when learning pure science, social science, and languages. Language demands more articulation at every level of imparting the expected knowledge to the kids or students. When Grammar and composition are taken, the level of perception of the students may not be the same as a result; they may find it a nut difficult to crack. Speech and comprehensive writing may go along with the tide but teaching and learning grammar may skip out of hand. Reasons for this may be divergent. Students tend to distract spectacularly in online classes compared to the regular class environment. One of the reasons may be that they do not interact with their peers or use phrases, similes, idioms with their classmates. On line, classes offer a great deal of less time to both teachers and students to teach and learn at their respective levels. Classwork and exercise may encumber in number since it is online. They cannot explore more and even hesitant to put into use what is learned in the online class. The pleasure of peer learning is denied to students. Learning the letter of any language, using it in the formation of words, etc., will not have challenges as expected. Owing to the lack of student's seriousness in online learning style, they may tend to cheat when it comes to the level of assessment in the form of examination. Habits of writing exercises diminished drastically because of online teaching unless they are provided with regular assignments. The threatening danger is in the missing of the physical presence of the faculty may be yet another reason for most of the students to get distracted easily as there no one to pull them back and the class getting ineffective.

Online technologies promoted the interface of distance and campus-based learning. In addition to increased interaction and interactivity between the teacher and pupil, it has accelerated the increase in offering opportunities to access the resources available with the pliability of place, space, and pace [14]. It is high time to think about redefining the exercise of online teaching more fertile and fruitful. It is necessary to train the online tutors to bring the best out of them in the synchronous and asynchronous online environment. It includes wider and general skills of dealing with the advantages of technology, social skills, and community building with creative language teaching skills, which in turn would develop a personal teaching style in an online medium [15].

In online communication, language learning and teaching identify the teacher as a reflective practitioner and the learner to be a motivated knowledge seeker. May it be an online or offline class for language 
learning, there is great scope for input and output to go hand in hand helping the learner with the interchangeability of these two variables. This is an exchange of knowledge among peers, between the learners and teachers as well as between learners and native speakers [10].

\section{METHODS AND STRATEGIES AVAILABLE FOR ONLINE TEACHING :}

The implementation of an online education system is expensive compared to traditional classrooms, particularly if multimedia and higher interactive methods are used. However, the costs used for its distribution are significantly lower than for conventional classrooms since they include maintenance of infrastructure facilities, time, travel expenses, etc. [16]. The use of technology is nothing new and is an essential part of our success as teachers and students. Figure 1 shows methods and strategies used for online teaching-learning.

(1) Content sharing: This includes non-interactive basic learning materials, interactive lectures, virtual displays, and learning aids. The first type of material, the non-interactive easy text-learning resource, contains text documents, presentations, video and audio content. Learners should just read, watch, or hear these contents without taking further action. These tools are easily and quickly developed. The web-based self-learning content includes a collection of interactive lessons consisting of text, graphics, animation, audio \& video, and interaction in the form of surveys, questions \& answers, and feedback. This type of content often provides information on additional resources in the form of web links to online resources and on-screen links to additional information on specific topics. Technical glossary, guides, online help, indexes, checklists, notes, etc. are just a few examples.

(2) Teamwork: It requires learners who share collective information and perform tasks. Collaborative activities include meetings and sharing of information, as well as involvement in a joint project. Online software is used for online communication learners, such as forums, message boards, and blogs. Students may discuss and share ideas throughout courses or contribute to group learning by sharing their information. Working in group projects means functioning with students to conduct a task [11]. The attention is on the development of learning and awareness-raising and upgrading of skills. The facilitator informs students about promoting and guiding critical thinking. This approach enables learners to interact, listen, debate and negotiate; interpersonal skills other than domain and problemsolving abilities are developed [12].

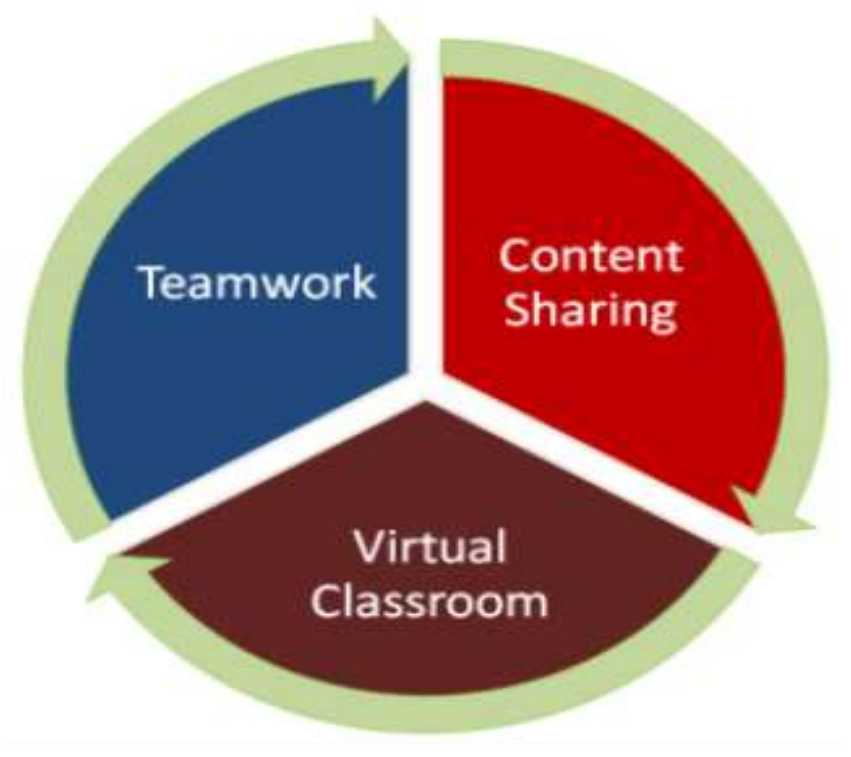

Fig. 1: Online Language teaching-learning Methods and strategies 
(3) Virtual classroom: A virtual classroom imitates a classroom run by a teacher with different types of synchronous resources, such as whiteboards, chat, and audio/video conferencing. They are entirely directed by a professor. A virtual classroom illustrates an e-learning environment in which an instructor uses various resources, such as slides, audio, or videos, to guide a group of students remotely in real time. Appropriate services must be in place for both students and providers. Digital classroom tools and strong internet access will serve this purpose [13].

\section{POSSIBILITIES AND OPPORTUNITIES :}

In essence, online education is an education offered via the Internet. It opens up many possibilities and obstacles for education in real time. It provides an excellent method for delivering education unbound by time or place, enabling content to be accessible from anywhere at any time. The ability to access educational materials from personal devices over the Internet $24 \mathrm{~h}$ a day provides a huge opportunity for learners to meet predefined academic and career goals without interruption. Online education would be highly satisfying, and it will be an exciting and motivating way to learn that is more interactive, more involved and more stimulating [14]. Students can attend classes, access course materials, complete course work, respond to questions, participate in discussions and submit assignments and take part in live or on-site quizzes [17]. There will be no transportation problems, no dispute with family commitments, no late arrivals, no classes due to sickness or any other excuse, and no attendance. The only prerequisite is to access the content of courses that submit assignments, participate in quizzes and provide feedback. No loss of teaching sessions due to strikes, natural calamities, or any other form of obstruction [18]. The online education format promotes a high degree of versatility in the interaction between teachers and students, as well as within the student community. Resources and ideas are shared and the continuous synergy created by the learning experience is developed as each pupil contributes in the curriculum discussion and reflects on the work of others [19]. The harmony of a student-centered virtual classroom is also one of the unique and important features of the online learning model. In online mode, students can customize class discussions to their particular needs and are in control of their own learning process. Technology is a lubricant for online education framework. The adaptation of modern and emerging technology has an effect on the system [17]. The development and progression of online education system has been aided by internet networking, cloud storage and computing, smart sensors, distributed databases, enhanced security systems, user-friendly programming languages, complex software convergence frameworks, and portable devices [20].

\section{PLATFORMS AND TOOLS :}

Online education is conducted using various synchronous and asynchronous ICCT resources. Some tools, such as wiki, blogs, emails, chats, are online tools, also called 'social media'. Some others, such as Google Meet, Zoom, Microsoft Team, Cisco WebEx, Zoom, help face-to-face interactions between teachers and students. In addition, a few resources, such as Google Classroom, Moodle, etc., build virtual classrooms that mimic real classrooms [21-22]. Some of them are discussed below:

(1) E-mail Tools: Emails are the easiest way to interact directly and individually between the facilitator/educator and students. E-mails could also be used for comments and replies that may be annoyed by the recipient if they are posted to a public place [19]. Newsletters could be used to send a message to the community or to express a modification or incidence to all participants. Only the instructor can send such messages, and not so often. Mailing lists can be used for discussion and paper sharing in small groups. They encourage cooperation between the project group and collaborative work. 
(2) Chat: Chat can be used as an online forum for questions and feedback. A chat may also be used for a specific event. Teachers can set up "breakout" sessions with some tools where small groups of learners hold meetings. Chat sessions have the advantage of adopting a text dialog.

(3) Instant Messaging: Instant Messaging is a common web-based application in the world. It allows two or more users to exchange text messages on a web-based or desktop-based platform in real time. In an area commonly known as the "Chat Room," a group of people may begin a text exchange online.

(4) Discussion Forums: Discussion forums are the key tool for online discussion. They encourage some participants to speak in the form of posted messages. In other words, at various times, participants can interact with others who can read and respond to comments that remain on the platform. One or more discussions could be included in each forum, comprising one or more comments and replies. Forums are used for thematic discussions, collective case studies, post-class comments, etc. [23]. Students and facilitators/teachers may leave messages, read and respond.

(5) Blogs: A blog (short of the Weblog) is a resource that allows people to share and obtain services without any need for computer programming expertise and to quickly update it. Blogs were structured to present content, much like a diary, as a simple entry list. A blog allows users to post material in a standardized format on a website regularly. Blogs allow information to be easily exchanged, viewed and modified. Learners may use them to apply their tasks and to comment on the tasks of others. Blogs may also be used as learning logs - a place to reflect, gather ideas and have smaller discussions [20].

(6) Webcasting: The term webcast refers to sounds and videos sent from a single source to multiple passive recipients. A standard application is a video lecture in which an expert speaks to many students, without interaction at the same time. Audio and video are transmitted over the Internet through webcaststreaming media. However, asynchronous applications can be assisted by recorded webcasts.

(7) Podcast: Podcasts are sound clips broadcast over the Internet. Audio files can be transferred to a compatible digital audio player or device. The facilitator can use videos to provide content, encouragement or instructions.

(8) Screen-sharing: Instant visual communication via screen sharing/whiteboards is possible. They provide an opportunity for students to access material and teachers to connect. Instructors should use whiteboards when the last-minute content adjustments and visual components are required for synchronous display. Sometimes, presentation need to be recorded. Two-way communication of whiteboards is also permitted. [21].

(9) Audio and video conferences: Audio and video conferences are real-time audio and video sessions for multiple users. They are mainly used for meetings and project updates. Voice over Internet Protocol (VoIP) applications and services allow users to make high-quality, low-cost calls over the Internet. Skype is a popular VoIP app in the world. Zoom, Jio Meet, Google Meet, Cisco WebEx, Skype, TeamViewer, GoToMeeting, BlueJeans are just a few examples [24].

(10) Virtual classroom: A virtual classroom is an online learning environment for students and teachers to communicate with each other. A virtual classroom imitates a classroom run by conventional teachers by adding a range of synchronous resources, such as whiteboard, chat, audio conference, or application sharing. Although the screen interface may be different, most virtual classroom devices have similar features. Examples include Vedamo, WizIQ, Adobe Link, Google Classroom, LearnCube, Moodle, BlackBoard Read, etc. [8]. 
(11) Online Video Channels: If we are prepared first, sharing the video is a lot easier. We are to include all of our videos in oour-training classroom and arrange them around subjects that relate to our training, e.g., verticals, case applications, or persona. Students will thus find the video on each video channel they are interested in. Examples include YouTube, Facebook, Yahoo Pages, VEVO, Vimeo, Fullscreen, Comcast, etc [25].

(12) Online Forms: Online Form is an online resource that enables tutors to collaboratively construct forms, surveys, tests, edit and share forms with other individuals. Educators will use methods to evaluate students and measure the existing knowledge at the start of the lesson [26-27]. Forms can also be used to provide input and feedback from students and parents. HubSpot, Google Forms, Microsoft Forms, SurveyAnyPlace, SurveyMonkey, FormTools, Forminator are just a few examples.

(13) Personal Websites: Teachers will own a personal website and share their expertise with people who want to learn. Teachers can use various teaching resources available, such as forums, videos, posts, live chats, to make the website more interactive. This will not only help students who belong to one teacher or class, but will also help those who need knowledge [28].

\section{ISSUES AND CHALLENGES :}

While the online education system is well recognized and accepted by most education providers of the day as it provides many advantages compared to its conventional counterpart, the system is not free from restrictions. The most critical problems of online learning are the limited accessibility of teachers and the lack of direct supervision of students. Restricted provision for group learning, reduced opportunities to socialize with teachers and students. The danger of data protection and privacy, increased reliance on technology and devices, confidence in the institution and willingness of students, and the need for additional training and instruction for both educators and pupils on digital presence are other challenges to the system. Online education continues to grow. Several innovations and resources are evolving daily to make the process more dynamic and applicable to everyone. There are plenty of amazing opportunities, and the framework must ingest them to remain relevant [29-32]. The framework can deliver improved teacher-student engagement, the ability to integrate with the tradition of face-toface education, make it simpler and more convenient by incorporating user-friendly, semi-automated, or fully automated tools, adapting newer educational paradigms, making them more adaptable to all forms of education and training, and ensuring data protection and integrity are opportunities. Keeping pace with ever-changing technology is a big challenge for the system. The challenges to be tackled in an online learning mode include continuous training and orientation for learners on the use of technology, remote monitoring of students, dealing with changing behaviors and attitudes of students, preserving data security, privacy, and dignity, and maintaining data protection, privacy, and dignity [33-37].

\section{BENEFITS AND DRAWBACKS :}

\subsection{Benefits:}

- Effective: Online teaching offers an efficient way to deliver lessons. Using digital learning materials such as videos, presentations, it is possible to make language teaching more effective and interesting. Sharing of learning resources is easy and the content can reach a large number of students [25].

- Ubiquitous: Online classes make the learning process ubiquitous. This is more helpful for students who are working or on internship. Online classes can be attended anytime anywhere. Students should have gadgets and Internet to access online lessons [38].

- Increased access and reach: Online teaching enables the learning process to occur anytime at any place as far as devices and connectivity are available. Conventional learning demands students to be present in the classrooms. Online classes can be accessed by a greater number of people as whoever has the link of online video can access the same. 
- Less Absenteeism: Since the recorded version of online classes is easily available to all the students, they can use the same to learn anytime. There is very little possibility of missing a class as the class.

- Affordability: Learning online is far more affordable than conventional one. The digital learning material is easily available.

- Encourage shy-natured students: During conventional class students who are withdrawn and feel hesitant to be at public glare can be turned into more promising ones as there is interaction with only the teacher and student. Since this environment is more comfortable for them, they easily openup with their teacher. This enables them to interact and learn language effortlessly.

- Easy assessment: Technology can assist teachers to evaluate the assignments effortlessly. Quizzes can be evaluated automatically [39].

- Flexible schedule: Digital learning materials can be downloaded on the device and can be accessed whenever the student is free. In case of conventional face-to-face learning, students are expected to attend classes regularly and the time table is fixed.

- Simplified learning: Teachers provide online learning material to the students. The digital content can be easily carried from one place to other rather than taking a bag of heavy text-books. Students can access the e-resources any time anywhere. This makes the learning process simple and easy [26].

\subsection{Drawbacks}

- The lack of activity-based learning: The conventional face-to-face language classes tend to be more interesting as they are full of activities such as debates, dialogues, games, contests, puzzles, stories, examples, anecdotes, stories, projects and group communication. These activities enable students learn how to use the language effectively. These types of activities are missing or cannot be conducted that effectively during online classes.

- Less opportunity for language immersion: Undoubtedly teaching language online will increase vocabulary and fluency. Using the right word at right place and make the sentence more effective requires effective discussion and interaction. History, idioms and phrases, gestures and feelings cannot be communicated that effectively using online teaching [31].

- Boredom and isolation: In the online classes, students sit alone and listen to the lecture in the virtual mode. Without the buzz of the classroom setting and company of peers, students often develop a sense of isolation and they find learning in an online mode less interesting. The rich learning experience that can be gained from associated learning is missing in the online classes

- The lack of self-discipline and motivation: The lazy nature of human beings, especially when there are no stringent rules or disciplinary actions, acts as a hindrance to the effectiveness of online classes. Students make several excuses to miss a session. E-learning is effective only when there is a strong desire to learn and self-motivation.

- The creation of digital content is time-consuming: Teachers should prepare digital learning material, quizzes, presentations and videos. The creation of digital content requires the language teacher to have expertise of using technology. The creation of digital content is time consuming [40].

\section{SUGGESTIONS :}

Online language learning requires a different approach to learning than pure science or social science. Multiple rules are expected to be implemented at different levels of language learning. Language needs further articulation at all levels of teaching students the expected knowledge, and the online learning mode will not replace the traditional classroom learning mode. Simply improve the classroom experience with online assistance without time constraints. More illustrations, resources are provided to students for improvement of language learning experience without replacing conventional face-toface learning. Some suggestions on the tools used are made on a group of topics involved in language teaching. For grammar and composition, webcasting, podcasting, multimedia networks and video and audio conferencing can be used to teach several students at the same time. Instant Messages will be used as online teaching methods for gathering reviews or suggestions on chats, along with more discussions. Discussion forums will be used to conduct discussions among students to evaluate the spirit 
and communication skills of students [19]. Blogs are typically used to post articles, thoughts on a subject that demonstrate learner writing skills and allow feedback from other viewers. Online forms such as Google Forms, Survey Any Place, and Form Tools are used for testing, reviews, assignment, and quiz purposes. They often encourage teachers to assess student types to examine the success of their learning [20].

\section{CONCLUSION :}

Revolutionary changes, with the advent of technology, have incredibly transformed the framework of teaching pedagogy. With the introduction of audio-visual aids to the sphere of teaching, teachers are facilitated with the process of teaching with pictures, audio clips, videos, presentations and posters along with the textbooks to make their teaching more colorful, meaningful and enjoyable. Online education has become a powerful alternative to conventional teaching. It enables ubiquitous learning. The online teaching platforms enable language teachers to conduct virtual classes effectively. A teacher should create a comfortable environment and ensure that all students are involved actively in the learning process. Learning language online requires more collaboration. Technologies such as instant messaging, chat rooms, message boards, virtual conferences, can be used to instill the language-learning desire among the students rather than evaluating the quizzes and assignments.

\section{REFERENCES :}

[1] Compton, L. K. L. (2009). Preparing language teachers to teach language online: A look at skills, roles, and responsibilities. Computer Assisted Language Learning, 22(1), 73-99.

[2] Yao, Yuxin, Ohinata, Asako, van Ours, Jan C. (2016). The educational consequences of language proficiency for young children. Economics of Education Review, 54(1), 1-15.

[3] Al Mamun, M. A. (2014). Effectiveness of Audio-Visual Aids in Language Teaching in Tertiary Level. Unpublished Master's Thesis, 1-52.

[4] Sreehari, P. (2012). Communicative language teaching: Possibilities and problems. English Language Teaching, 5(12), 87-93.

[5] Marie, L. (2007). Online communication in language learning and teaching. New York, 112-121.

[6] Stern, J. (2018). Introduction to Online Teaching and Learning. International Journal of Science Education, 3(1), 1-10.

[7] Bennett, S., \& Lockyer, L. (2004). Becoming an online teacher: Adapting to a changed environment for teaching and learning in higher education. Educational Media International, 41(3), 231-248.

[8] Meyer, K. A. (2003). Face-to-face versus threaded discussions: The role of time and higher-order thinking. Journal of Asynchronous Learning Networks, 7(3), 55-65.

[9] Hampel, R., \& Stickler, U. (2005). New skills for new classrooms: Training tutors to teach languages online. Computer assisted language learning, 18(4), 311-326.

[10] Bennett, S., \& Lockyer, L. (2004). Becoming an online teacher: Adapting to a changed environment for teaching and learning in higher education. Educational Media International, 41(3), 231-248.

[11] Rajeshwari M \& Krishna Prasad K, (2020). An insight into the architecture, technologies and applications of Cognitive Computing, Information, Communications and Computation Technology (ICCT), ISBN: 978-93-88879-95-8, New Delhi Publishers, pp. 141-171

[12] Laal, M., \& Ghodsi, S. M. (2012). Benefits of collaborative learning. Procedia-social and behavioral sciences, 31(1), 486-490.

[13] Resta, P., \& Laferrière, T. (2007). Technology in support of collaborative learning. Educational Psychology Review, 19(1), 65-83.

[14] Shih, Y. C., \& Yang, M. T. (2008). A collaborative virtual environment for situated language learning using VEC3D. Journal of Educational Technology \& Society, 11(1), 56-68. 
[15] Loertscher, D. V., \& Koechlin, C. (2013). Online learning: Possibilities for a participatory culture. Teacher librarian, 41(1), 50-53.

[16] Kim, J., \& Lee, W. (2011). Assistance and possibilities: Analysis of learning-related factors affecting the online learning satisfaction of underprivileged students. Computers \& Education, 57(4), 2395-2405.

[17] Salmons, J. (2020, March 16). Making a Sudden Transition to Teaching Online: Suggestions and Resources. Retrieved from https://www.socialsciencespace.com/ 2020/03/making-a-suddentransition-to-teaching-online-suggestions-and-resources/ on December 20, 2020.

[18] Shen, D., Cho, M. H., Tsai, C. L., \& Marra, R. (2013). Unpacking online learning experiences: Online learning self-efficacy and learning satisfaction. The Internet and Higher Education, 19, 1017.

[19] Deming, D. J., Goldin, C., Katz, L. F., \& Yuchtman, N. (2015). Can online learning bend the higher education cost curve? American Economic Review, 105(5), 496-501.

[20] Lim, C. P. (2004). Engaging learners in online learning environments. Tech Trends, 48(4), 16-23.

[21] Abuhassna, H., Al-Rahmi, W. M., Yahya, N., Zakaria, M. A. Z. M., Kosnin, A. B. M., \& Darwish, M. (2020). Development of a new model on utilizing online learning platforms to improve students' academic achievements and satisfaction. International Journal of Educational Technology in Higher Education, 17(1), 1-23.

[22] Vinayachandra, \& Krishna Prasad, K. (2020). Application of IoT in the Development of Intelligent Education System - A Thematic Literature Review. International Journal of Management, Technology, and Social Sciences (IJMTS), 5(1), 124-146

[23] Richards, R. (2010). Digital citizenship and web 2.0 tools. MERLOT Journal of online learning and teaching, 6(2), 516-522.

[24] Esani, M. (2010). Moving from face-to-face to online teaching. Clinical Laboratory Science: Journal of the American Society for Medical Technology, 23(3), 187-190.

[25] Forrester, D. (2009). Global Connections: Web Conferencing Tools Help Educators Collaborate Anytime, Anywhere. Learning \& Leading with Technology, 36(5), 24-25.

[26] Sherer, P., \& Shea, T. (2011). Using online video to support student learning and engagement. College Teaching, 59(2), 56-59.

[27] Vinayachandra \& Krishna Prasad K (2021). ICCT implementation in the transition from traditional in-class, face-to-face teaching to remote learning - a study, Information, Communications and Computation Technology (ICCT), ISBN: 978-93-88879-95-8, New Delhi Publishers, 55-86.

[28] Redmond, P. (2011). From face-to-face teaching to online teaching: Pedagogical transitions. ASCILITE 2011 - The Australasian Society for Computers in Learning in Tertiary Education, 2002, 1050-1060.

[29] Lee, K. (2017). Rethinking the accessibility of online higher education: A historical review. The Internet and Higher Education, 33(1), 15-23.

[30] Zhao, Fang (2003). Enhancing the quality of online higher education through measurement. Quality Assurance in Education, 11(4), 214-221

[31] Hoic-Bozic, N., Mornar, V., \& Boticki, I. (2008). A blended learning approach to course design and implementation. IEEE transactions on education, 52(1), 19-30.

[32] Kler, S. (2014). ICT Integration in Teaching and Learning: Empowerment of Education with Technology. Issues and Ideas in Education, 2(2), 255-271.

[33] Moore, J. L., Dickson-Deane, C., \& Galyen, K. (2011). E-Learning, online learning, and distance learning environments: Are they the same? Internet and Higher Education, 14(2), 129-135. 
[34] Zhang, W., \& Sun, Y. (2018). The study on the support of online learning resource in blended learning based on learning process. Proceedings - 6th International Conference of Educational Innovation Through Technology, EITT 2017, 2018-March, 242-243.

[35] Lee, L. (2016). Autonomous learning through task-based instruction in fully online language courses. Language Learning \& Technology, 20(2), 81-97.

[36] Chenoweth, N. A., Ushida, E., \& Murday, K. (2006). Student learning in hybrid French and Spanish courses: An overview of language online. CALICO journal, 24(1), 115-146.

[37] Differences Between Online and Face to Face Courses. Retrieved from https://miamioh.edu/regionals/academics/elearning/ecampus-faculty-staff/eccoenews/2019/01/differences-between-f2f-and-online.html on December 20, 2020.

[38] Learn why today's new remote teaching experience is not the same as established online courses. (2020, April 16). Retrieved from https://www.grantham.edu/blog/remote-teaching-vs-onlinelearning-in-higher-education-today/ on December 20, 2020.

[39] Gunn, C. (2010). Sustainability factors for e-learning initiatives. ALT-J, 18(2), 89-103

[40] Napier, N. P., Dekhane, S., \& Smith, S. (2011). Transitioning to blended learning: Understanding student and faculty perceptions. Journal of Asynchronous Learning Network, 15(1), 20-32.

$* * * * * * * * * * * * * *$ 